\title{
Uso de regulador de crescimento na cultura da batata-doce
}

\section{Effects of a plant growth regulator on sweet potato plants}

\author{
Amarílis Beraldo RÓs ${ }^{1}$; Nobuyoshi NARITA²; Humberto Sampaio de ARAÚJO \\ ${ }^{1}$ Autor para correspondência. Pesquisadora científica, $\mathrm{Dr}^{\mathrm{a}}$ em Agronomia, Agência Paulista de Tecnologia \\ dos Agronegócios, Polo Alta Sorocabana. Rodovia Raposo Tavares, km 561, Caixa Postal 298, CEP: \\ 19015-970, Presidente Prudente, SP. amarilis@apta.sp.gov.br \\ ${ }^{2}$ Pesquisador científico, Dr. em Agronomia, Agência Paulista de Tecnologia dos Agronegócios, Polo Alta \\ Sorocabana. Rodovia Raposo Tavares, km 561, Caixa Postal 298, CEP: 19015-970, Presidente Prudente, \\ SP.narita@apta.sp.gov.br \\ ${ }^{3}$ Pesquisador científico, Ms. em Agronomia, Agência Paulista de Tecnologia dos Agronegócios, Polo \\ Extremo Oeste. Estrada Vicinal Nemezião de Souza Pereira, km 06, Caixa Postal 67, CEP 16900-970, \\ Andradina/SP. humbertosaraujo@apta.sp.gov.br
}

Recebido em: 23-04-2014; Aceito em: 04-11-2014

\section{Resumo}

O uso de reguladores de crescimento na agricultura tem demonstrado, por meio de pesquisas, potencial para o aumento da produtividade de determinadas culturas. No entanto, estudos com o uso desses produtos em culturas cuja porção comercial é composta por raízes são escassos. Neste trabalho, objetivou-se avaliar a influência do regulador de crescimento Stimulate ${ }^{\circledR}$ sobre o crescimento inicial de plantas de batata-doce e a produtividade de raízes tuberosas por ocasião da colheita. Foram conduzidos dois experimentos, nos quais segmentos de ramas de batata-doce foram parcialmente imersos em soluções contendo o produto. Em casa de vegetação, o delineamento experimental foi inteiramente ao acaso, em esquema fatorial $6 \times 6$, sendo seis doses do regulador de crescimento $\left(0 ; 3 ; 6 ; 9 ; 12\right.$ e $\left.15 \mathrm{~mL} \mathrm{~L}^{-1}\right)$ e seis épocas de coleta (10; 19; 28; 37; 46 e 55 dias após o plantio) de raízes adventícias e folhas. No campo, o delineamento experimental foi em blocos ao acaso, sendo os tratamentos constituídos por seis doses de regulador de crescimento $\left(0 ; 3 ; 6 ; 9 ; 12\right.$ e $\left.15 \mathrm{~mL} \mathrm{~L}^{-1}\right)$. O regulador de crescimento influenciou sobre o número de raízes adventícias, e o número e a massa seca de folhas por planta. A produtividade de raízes tuberosas não diferiu, sendo os valores médios de 27,5 e $25,8 \mathrm{t} \mathrm{ha}^{-1}$ para produtividades total e comercial, respectivamente. Assim, o regulador de crescimento promove incremento no número de raízes adventícias de plantas de batata-doce, mas não favorece a produtividade de raízes tuberosas até a dose de $15 \mathrm{~mL} \mathrm{~L}^{-1}$.

Palavras-chave adicionais: biorregulador; crescimento; Ipomoea batatas (L.) Lam.; produtividade; Stimulate ${ }^{\circledR}$.

\begin{abstract}
Research results have shown that the application of plant growth regulators to crop species has permitted increased yields. However, this technique has been sparsely applied to crops whose commercial parts are comprised by roots. The objective of this study was to evaluate the influence of plant growth regulator Stimulate@ on the initial growth of sweet potato plants and on the productivity of tuber roots at harvest time. Two experiments were carried out by which sweet potato plant branches were partially immersed in solutions containing the product. In a greenhouse experiment, the plants were, in accordance with a completely random design, exposed to 6 doses of the plant regulator $\left(0,3,6,9,12\right.$, and $\left.15 \mathrm{~mL} \mathrm{~L}^{-1}\right)$ and the resulting plants harvested 10, 19, 28, 37, 46, and 55 days after planting. Adventitious roots and leaves were harvested. In a field experiment, in a randomized complete block design, the plants were exposed to the same doses of the greenhouse experiment. The product influenced the number of adventitious roots, the number and dry weight of leaves per plant. Tuber roots productivity was not influenced by the treatments. 27.5 and $25.8 \mathrm{t} \mathrm{ha}^{-1}$ of tuber roots were the mean total and marketable yields, respectively. So, the plant growth regulator favors the increment in adventitious roots number but has no influence on the yield of tuber roots up to the dose of $15 \mathrm{~mL} \mathrm{~L}^{-1}$.
\end{abstract}

Additional keywords: bioregulator; growth; Ipomoea batatas (L.) Lam.; Stimulate ${ }^{\circledR}$; yield.

\section{Introdução}

A cultura da batata-doce apresenta expressiva importância no Brasil, sendo produzida em 21 unidades da federação (IBGE, 2011). Trata-se de uma planta de fácil cultivo, podendo produzir mais de $30 \mathrm{t} \mathrm{ha}^{-1}$ em condições adequadas (Rós et al., 2013).

A parte comercial da cultura da batata-doce caracteriza-se por suas raízes tuberosas, podendo-se supor que a utilização de reguladores de crescimento 
que estimulem a emissão de raízes adventícias poderia favorecer a absorção de água e nutrientes, permitindo maior acúmulo de substâncias de reserva nas raízes tuberosas, incrementando a produtividade. Segundo Vieira \& Castro (2002), o regulador de crescimento Stimulate ${ }^{\circledR}$, composto por ácido indolbutírico $\left(0,05 \mathrm{~g} \mathrm{~L}^{-1}\right)$, cinetina $\left(0,09 \mathrm{~g} \mathrm{~L}^{-1}\right)$ e ácido giberélico $\left(0,05 \mathrm{~g} \mathrm{~L}^{-1}\right)$, pode, em função de sua composição, concentração e proporção das substâncias, incrementar o crescimento e o desenvolvimento vegetal, estimulando a divisão celular e, também, aumentar a absorção de água e de nutrientes pelas plantas.

As giberelinas, auxinas e citocininas atuam na divisão celular, no alongamento celular, na quebra de dormência de gemas, no aumento dos tecidos meristemáticos e no transporte de nutrientes (Taiz \& Zeiger, 2012). Contudo, esses efeitos dependem da concentração, da natureza e da proporção das substâncias presentes nos produtos (Vieira, 2001).

De acordo com o rótulo do produto Stimulate ${ }^{\circledR}$, sua utilização promove o crescimento e o desenvolvimento vegetal, destacando-se maior enraizamento e, portanto, maior absorção de água e nutrientes pelas plantas, fato confirmado em trabaIho de Reghin et al. (2000), no qual a utilização de Stimulate $\mathrm{Mo}^{\circledR}$ (reguladores de crescimento e 4\% de molibdênio) promoveu incremento do número e do comprimento de raízes de mudas de mandioquinha-salsa. Além de alterações no sistema radicular, Tecchio et al. (2005), Ataíde et al. (2006) e Vieira et al. (2008) verificaram que os reguladores vegetais presentes no produto, quando aplicados em conjunto, tendem a estimular a planta a aumentar o número de brotações. Contudo, a propagação por estaquia de pinheira, gravioleira e atemoeira, mediante imersão em diferentes concentrações do Stimulate ${ }^{\circledR}$, não foi considerada viável segundo Silva (2008), visto que a utilização do produto resultou em menores porcentagens de enraizamento, de sobrevivência das estacas e de estacas com calos, bem como reduziu o número e o comprimento das raízes em relação à testemunha, sem aplicação do regulador de crescimento.

Os dados sobre os efeitos do uso de regulador de crescimento Stimulate ${ }^{\circledR}$ na agricultura ainda são bastante divergentes. Na cultura da soja, por exemplo, Bertolin et al. (2010) observaram que o produto proporcionou incremento na produtividade de grãos, tanto em aplicação via sementes quanto via foliar. Na mesma cultura, Dario et al. (2005) observaram que a utilização do mesmo produto, em diversas formas de aplicação, não alterou sua produtividade.

Dessa forma, neste trabalho, objetivou-se verificar a influência de diferentes doses do regulador de crescimento Stimulate ${ }^{\circledR}$ sobre o crescimento inicial de plantas de batata-doce e a produtividade de raízes tuberosas por ocasião da colheita.

\section{Material e métodos}

Foram realizados dois trabalhos na Agência Paulista de Tecnologia dos Agronegócios - Polo Alta Sorocabana, no município de Presidente Prudente, a $22^{\circ} 11^{\prime}$ de latitude $\mathrm{S}$ e $51^{\circ} 23^{\prime}$ de longitude W Gr. O clima é Aw, segundo classificação de Köppen, sendo tropical chuvoso com inverno seco (CEPAGRI, 2014).

Para a avaliação do crescimento inicial de plantas de batata-doce, conduziu-se experimento inteiramente ao acaso, em esquema fatorial $6 \times 6$, sendo 6 doses de Stimulate ${ }^{\circledR}(0 ; 3 ; 6 ; 9 ; 12$ e $\left.15 \mathrm{~mL} \mathrm{~L}^{-1}\right)$ e seis épocas de coleta $(10 ; 19 ; 28 ; 37$; 46 e 55 dias após o plantio (DAP)), correspondendo a 36 tratamentos, com cinco repetições, totalizando 180 unidades experimentais. Cada parcela foi constituída por dois copos, com uma planta cada, ou seja, foram utilizados 360 copos.

O trabalho foi conduzido em casa de vegetação envolta em tela plástica, durante o período de setembro a novembro de 2012. Foram utilizados segmentos de ramas de batata-doce com $0,3 \mathrm{~m}$ de comprimento, contendo de 9 a 10 gemas, obtidos de plantas da variedade Uruguaiana, cultivadas a campo. Os segmentos foram retirados da porção apical das ramas (até $0,6 \mathrm{~m}$ ). As folhas foram retiradas com tesoura de poda, tomando-se o cuidado de não ferir as gemas.

Os segmentos tiveram sua porção basal (10 cm contendo 3 gemas) imersa em recipiente contendo soluções com crescentes doses do regulador de crescimento Stimulate ${ }^{\circledR}$, por 15 minutos. Após secagem ao ar, parte dos segmentos $(6 \mathrm{~cm})$ foi inserida em substrato comercial produzido à base de vermiculita, acrescido de casca de pínus (Bioplant $^{\circledR}$ ) acondicionado em copos plásticos com $0,15 \mathrm{~m}$ de altura, diâmetros superior e inferior com 9,5 e $6,0 \mathrm{~cm}$, respectivamente, e capacidade para $700 \mathrm{~mL}$. O substrato foi irrigado uma vez ao dia, por todo o período do experimento, com quantidade de água que proporcionasse a eliminação de poucas gotas de água pelo furo de drenagem dos copos.

Foram avaliados o número de segmentos que emitiram raízes e brotações na parte aérea, bem como o número e a massa seca de raízes adventícias e de folhas por unidade de planta, nas seis épocas de coleta. Para o cálculo da porcentagem de segmentos enraizados e com brotações, foram somados os números de segmentos com raízes e brotações obtidos em cada época de coleta, e o valor foi transformado em porcentagem. Para a quantificação do número e da massa seca de raízes e folhas, foram consideradas as raízes que saíam diretamente do segmento plantado, e as folhas com limbo com dimensão igual ou superior a $1,5 \mathrm{~cm}$. Para a medição da massa seca, o material colhido, tanto da parte aérea como das raízes, foi colocado em estufa com circulação forçada de ar mantida à temperatura constante de $65^{\circ} \mathrm{C}$, até atingir valores constantes. 
Para avaliar a produtividade de raízes tuberosas de batata-doce, foi conduzido experimento a campo. O delineamento experimental foi em blocos ao acaso, sendo os tratamentos compostos por seis doses de Stimulate ${ }^{\circledR}\left(0 ; 3 ; 6 ; 9 ; 12\right.$ e $\left.15 \mathrm{~mL} \mathrm{~L}^{-1}\right)$, com cinco repetições. Os segmentos de ramas de batata-doce foram preparados segundo os mesmos procedimentos descritos anteriormente, mas permaneceram nas soluções com o regulador de crescimento por 30 minutos. Após a secagem dos segmentos ao ar, eles foram plantados, em março de 2013, em área de Argissolo Vermelho-Amarelo, com o seguinte resultado de análise química na camada de 0 a $0,15 \mathrm{~m}: \mathrm{pH}\left(\mathrm{CaCl}_{2} 1,0 \mathrm{~mol} \mathrm{~L}^{-1}\right)$ 5,2; $41,2 \mathrm{mg} \mathrm{dm}^{-3}$ de PMehlich; $6,1 \mathrm{~g} \mathrm{dm}^{-3}$ de C; $3,04 \mathrm{cmol}_{\mathrm{C}} \mathrm{dm}^{-3}$ de $\mathrm{H}+\mathrm{Al} ; 0,3 \mathrm{cmol}_{\mathrm{c}} \mathrm{dm}^{-3}$ de $\mathrm{K}$; $1,4 \mathrm{cmol}_{\mathrm{c}} \mathrm{dm}^{-3}$ de $\mathrm{Ca} ; 1,18 \mathrm{cmol}_{\mathrm{c}} \mathrm{dm}^{-3}$ de $\mathrm{Mg} ; 47 \%$ de saturação por bases. Não houve correção ou adubação do solo.

O solo foi preparado por meio de aração, gradagem e confecção de leiras com sulcador. Cada parcela experimental de $16,2 \mathrm{~m}^{2}(2,7 \times 6 \mathrm{~m})$ foi composta por três leiras distanciadas $0,9 \mathrm{~m}$, onde foram plantadas 20 ramas de $0,3 \mathrm{~m}$ cada, espaçadas a cada $0,3 \mathrm{~m}$, o que correspondeu a 37.000 plantas ha ${ }^{-1}$. O plantio nas leiras, com altura aproximada de $0,35 \mathrm{~m}$, foi realizado com abertura manual de cova com $0,08 \mathrm{~m}$ de profundidade, colocação vertical da base da rama e enterrio manual.

Aos 150 DAP, foi realizada a colheita das raízes tuberosas da área útil, ou seja, das 18 plantas centrais da leira do meio. Foram avaliadas as produtividades total e comercial. Para produtividade total, foram consideradas todas as raízes tuberosas com massa fresca igual ou superior a $40 \mathrm{~g}$, enquanto para a produtividade comercial, as raízes tuberosas com massa fresca entre 80 e $1.000 \mathrm{~g} \mathrm{e}$ bom aspecto (formato uniforme e liso).

Os dados relativos à massa seca de raízes adventícias e folhas foram transformados mediante emprego da equação $(x+1)^{1 / 2}$, em função da presença de valores próximos a zero. Os dados obtidos para cada variável analisada foram submetidos à análise de variância, e as médias foram ajustadas a equações de regressão polinomial. Os pontos de máximos foram determinados por derivação das equações de regressão de segundo grau. Os dados obtidos na avaliação da produtividade de raízes tuberosas foram submetidos à análise de variância. Adotaram-se, no máximo, $5 \%$ de probabilidade de erro.

\section{Resultados e discussão}

Em casa de vegetação, a batata-doce apresentou $98 \%$ de seus segmentos enraizados e com brotações, não havendo diferença estatística na porcentagem de segmentos enraizados em função das doses do regulador de crescimento Stimulate ${ }^{\circledR}$. Esse resultado difere do observado por Silva (2008), em que estacas de pinheira, gravioleira e atemoeira, tratadas com Stimulate ${ }^{\circledR}$ nas doses de $0 ; 2 ; 4 ; 6$ e $8 \mathrm{~mL} \mathrm{~L}^{-1}$, apresentaram menores percentuais de enraizamento quando utilizadas as maiores doses do produto. Segundo o autor, o fato poderia estar relacionado à presença do ácido giberélico (GA3) que pode ter inibido o enraizamento em favor do desenvolvimento de brotações. No presente trabaIho, em função de não ter ocorrido diferença estatística na porcentagem de enraizamento de segmentos submetidos aos diferentes tratamentos, o elevado número de estacas enraizadas era esperado, visto que, de acordo com Rós et al. (2011), as estacas dessa cultura apresentam facilidade de enraizamento e emissão de folhas, podendo atingir a porcentagem de $100 \%$ de estacas enraizadas, dependendo da cultivar.

Não houve interação entre doses e épocas de coleta nas características número e massa seca de raízes adventícias por planta. O número de raízes variou em função dos dois fatores, enquanto sua massa seca, apenas em função da época de coleta.

O número de raízes adventícias por planta ajustou-se segundo modelo quadrático, em função da dose de Stimulate ${ }^{\circledR}$, com acréscimos até o ponto de máxima eficiência estimada, que ocorreu na dose de 8,2 $\mathrm{mL} \mathrm{L}^{-1}$ (Figura 1). A utilização de doses superiores a essa resultou em redução do número de raízes adventícias por planta, demonstrando o efeito negativo de doses elevadas sobre a característica. Esse comportamento pode estar relacionado ao fato de as estacas possuírem certa quantidade endógena de hormônios, promotores ou inibidores de enraizamento, e o fornecimento exógeno de auxina, em certas quantidades, pode promover uma alteração hormonal, favorecendo ou não o enraizamento (Ramos et al., 2003). Dutra et al. (1999) também verificaram resposta segundo modelo quadrático para a característica número de raízes por planta, concluindo que a utilização de ácido indolbutírico no enraizamento de estacas de pessegueiro afeta sua qualidade. Em pinheira, gravioleira e atemoeira, Silva (2008) contabilizou redução no número de raízes em estacas tratadas com as maiores doses de Stimulate ${ }^{\circledR}$ testadas (6 e $8 \mathrm{~mL} \mathrm{~L}^{-1}$ ).

Em trabalho de Reghin et al. (2000), foram testadas doses de Stimulate $\mathrm{Mo}^{\circledR}$ em mudas de mandioquinha-salsa e foi verificado que até a dose de $10 \mathrm{~mL} \mathrm{~L}^{-1}$ o número de raízes por planta apresentou resposta segundo modelo linear, com acréscimos a cada aumento na dose do regulador de crescimento, diferentemente do presente trabalho. Resposta favorável também foi obtida por Mayer et al. (2001), que verificaram que a imersão das estacas herbáceas de umezeiro em solução contendo $2.000 \mathrm{~g}$ de AIB por litro de água resultou em maior número de raízes por estaca em comparação à não utilização do regulador de crescimento do tipo auxínico. 
O número de raízes adventícias por planta aumentou com o incremento da época de coleta, com ajuste segundo modelo linear (Figura 2). Dessa forma, até o período de 55 DAP, as plantas de batata-doce continuaram emitindo novas raízes a partir do segmento utilizado para plantio, o que era esperado, pois as plantas encontravam-se em fase inicial de crescimento e desenvolvimento.

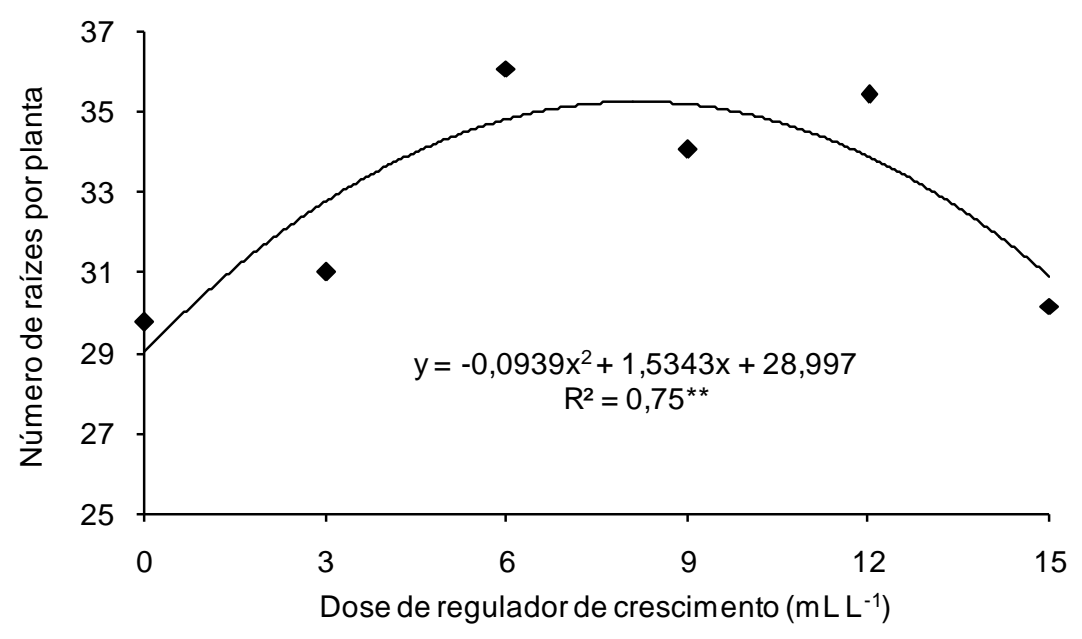

Figura 1 - Número de raízes adventícias por planta em função das diferentes doses de regulador de crescimento. ${ }^{* *}$ Significativo a $1 \%$ de probabilidade, pelo teste $\mathrm{F}$. Number of adventitious roots per plant as a function of different plant growth stimulant doses. ${ }^{* *}$ Significant at the level of $1 \%$ of probability according to the F-test.

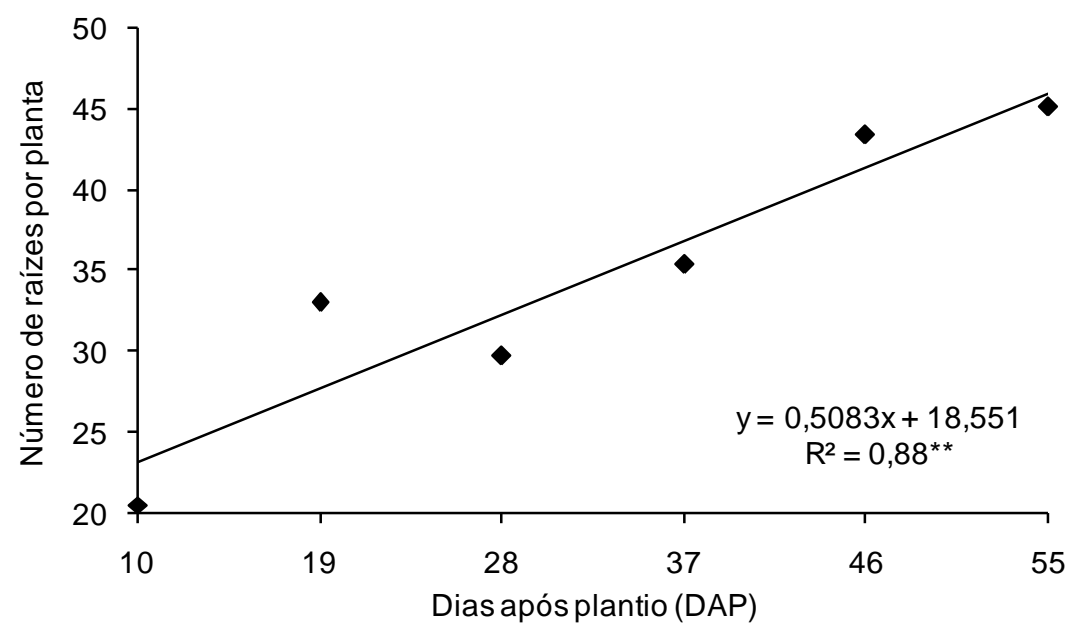

Figura 2 - Número de raízes adventícias por planta em função da época de coleta. ${ }^{*}$ Significativo a $1 \%$ de probabilidade, pelo teste F. Number of adventitious roots per plant as a function of evaluation time. ** Significant at the level of $1 \%$ of probability according to the F-test.

A massa seca de raízes adventícias por planta não foi influenciada pela aplicação de diferentes doses do regulador de crescimento Stimulate ${ }^{\circledR}$, apresentando valor médio de $1,14 \mathrm{~g}$ por planta, mas variou entre as épocas de coleta (Figura 3). A resposta estimada foi segundo modelo linear, com incremento em seu valor, em função da maior permanência das plantas nos copos, o que, da mesma forma que em relação ao número de raízes adventícias, era esperado. Assim, o aumento da massa seca de raízes adventícias em função da época de coleta está relacionado ao acréscimo no número de raízes, bem como ao desenvolvimento e ao crescimento de raízes no tempo.
De maneira semelhante a este trabalho, Candido et al. (2012) verificaram que a imersão de estacas de canelinha em solução de $5 \mathrm{~mL} \mathrm{~L}^{-1}$ de Stimulate $^{\circledR}$ não proporcionou resultados diferentes da testemunha em várias características avaliadas, entre elas a massa seca de raízes. Contudo, Dutra et al. (1999) observaram que estacas de pessegueiro apresentaram incremento no número e na massa seca de raízes quando utilizado ácido indolbutírico até a dose de $2.318 \mathrm{mg} \mathrm{L}^{-1}$. Cato (2006) verificou que a aplicação de Stimulate ${ }^{\circledR}$ promoveu incrementos significativos no acúmulo de massa seca nas raízes em tomateiro com relação ao controle. Gontijo et al. (2003) verificaram incrementos crescentes no núme- 
ro e na massa seca de raízes com a imersão da base de estacas de aceroleira em ácido indolbutírico até à dose máxima estudada $\left(2.800 \mathrm{mg} \mathrm{L}^{-1}\right)$, o que foi justificado como efeito benéfico da auxina no sistema radicular. Dessa forma, verifica-se que cada cultura apresenta resposta específica no enraizamento quando suas estacas são imersas em reguladores de crescimento.

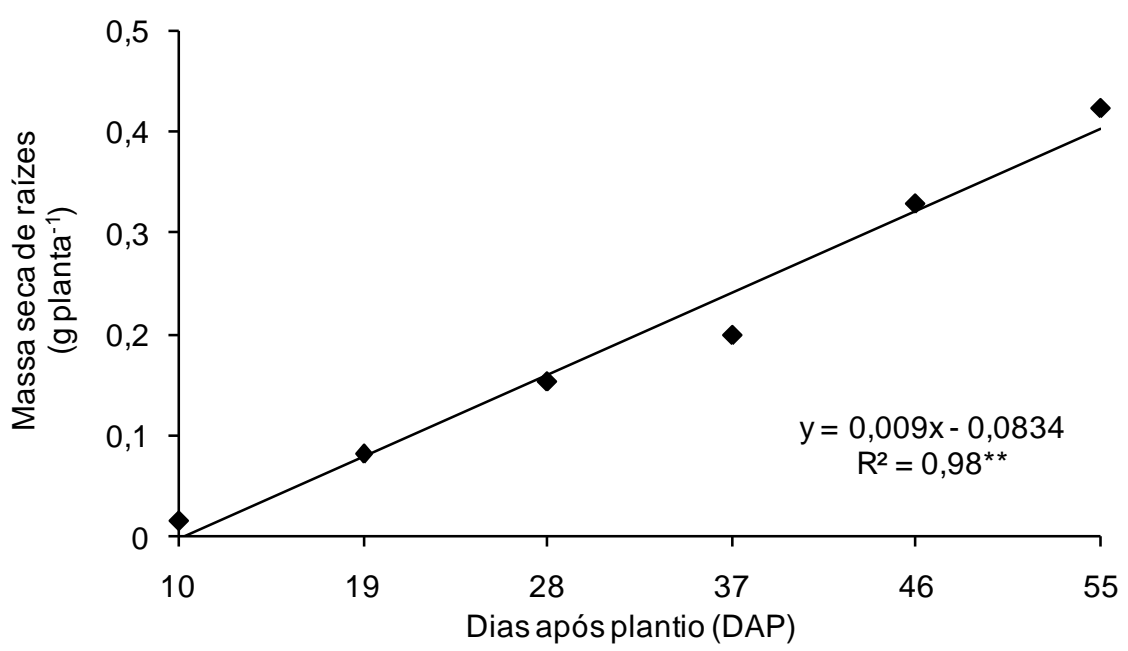

Figura 3 - Massa seca de raízes adventícias por planta em função da época de coleta. **Significativo a $1 \%$ de probabilidade, pelo teste F. Dry mass of adventitious roots per plant as a function of evaluation time. ** Significant at the level of $1 \%$ of probability according to the F-test.

Os resultados obtidos confirmam a atuação de Stimulate ${ }^{\circledR}$ como estimulador do sistema radicular até a dose de $8,2 \mathrm{~mL} \mathrm{~L}^{-1}$, quando houve aumento de $21 \%$ no número de raízes, em relação à não utilização do produto, o que pode favorecer a absorção de água e de nutrientes pela planta, embora não tenha ocorrido incremento de massa seca de raízes em função do uso do regulador de crescimento. Tal fato indica que o produto Stimulate ${ }^{\circledR}$ favoreceu a emissão de raízes até a dose de $8,2 \mathrm{~mL} \mathrm{~L}^{-1}$, mas estas se apresentaram mais finas que as obtidas no tratamento-testemunha.

Em relação às variáveis número de folhas e massa seca das mesmas, houve interação entre fatores doses de Stimulate ${ }^{\circledR}$ e épocas de coleta, mas não em todas as épocas. No número de folhas, a interação significativa ocorreu apenas nas épocas de 28 e 46 DAP, enquanto na massa seca de folhas, aos 28; 37 e 46 DAP.

O número de folhas por planta não foi influenciado pela utilização de Stimulate ${ }^{\circledR}$ aos 10; 19; 37 e 55 DAP, sendo seus valores médios de 4,9; 12,6; 22,1 e 20, respectivamente. Nos demais períodos, 28 e 46 DAP, houve incremento do número de folhas com o aumento da dose do regulador de crescimento até os valores de 8,6 e $9,8 \mathrm{~mL} \mathrm{~L}^{-1}$, quando foram atingidos os valores estimados de 29,7 e 32,0 folhas por planta, respectivamente (Figura 4).

Em estacas de figueira, Pio et al. (2006) não verificaram influência da aplicação de $2.000 \mathrm{mg} \mathrm{L}^{-1}$ de ácido indolbutírico no número de folhas por planta, enquanto Villa et al. (2003) constataram que a utilização de AIB no enraizamento de estacas de amoreira-preta, variedade Brazos, promoveu redu- ção em todas as variáveis estudadas, incluindo porcentagem de enraizamento e número de folhas, o que foi atribuído à possibilidade de as estacas já apresentarem conteúdo endógeno de auxinas apropriado para o processo de enraizamento, e a aplicação de AIB possivelmente tenha induzido um efeito fitotóxico nas estacas.

A massa seca de folhas por planta não foi influenciada pela utilização do produto aos 10; 19 e 55 DAP, sendo seus valores médios de 0;0,56 e $2,17 \mathrm{~g}$, respectivamente. Nas demais épocas, $28 ; 37$ e 46 DAP, houve respostas estimadas segundo modelo linear (Figura 5). Em 28 e 37 DAP, houve redução no valor de massa de folhas com 0 aumento das doses. Em 46 DAP, ao contrário, houve aumento dos valores da característica com a utilização de doses mais elevadas do produto.

Quando o número (Figura 4) e a massa seca de folhas (Figura 5) são relacionados, verifica-se que, aos 28 DAP, mesmo quando houve incremento do número de folhas até à dose de $8,6 \mathrm{~mL} \mathrm{~L}^{-1}$, foi verificada diminuição de sua massa seca, o que indica que as folhas, embora em maior número, apresentaram-se menores ou com menor massa seca individual. Aos 37 DAP, o número estimado de folhas foi constante, visto que não houve interação entre doses de Stimulate ${ }^{\circledR}$ e épocas de coleta nesta data. No entanto, houve variação na massa seca, o que também indica variação no tamanho e/ ou na massa individual de folhas em função das doses utilizadas. $\mathrm{Na}$ coleta realizada aos 46 DAP, houve acréscimo no número de folhas até $9,8 \mathrm{~mL} \mathrm{~L}^{-1}$, mas crescente aumento de massa seca, indicando que, a partir dessa dose, a massa seca individual de folha aumentou. 


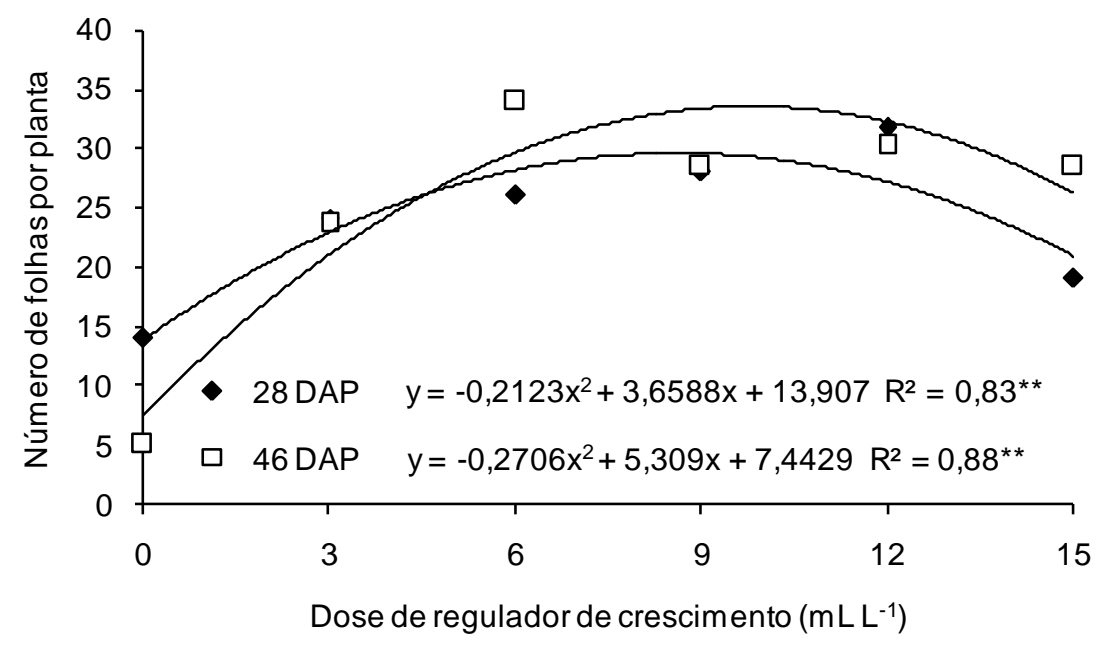

Figura 4 - Número de folhas por planta em função das diferentes doses de regulador de crescimento. ${ }^{*}$ Significativo a $5 \%$ de probabilidade, pelo teste $\mathrm{F}$. Leaves number per plant as a function of different plant growth stimulant doses. ${ }^{*}$ Significant at the level of $5 \%$ of probability according to the F-test.

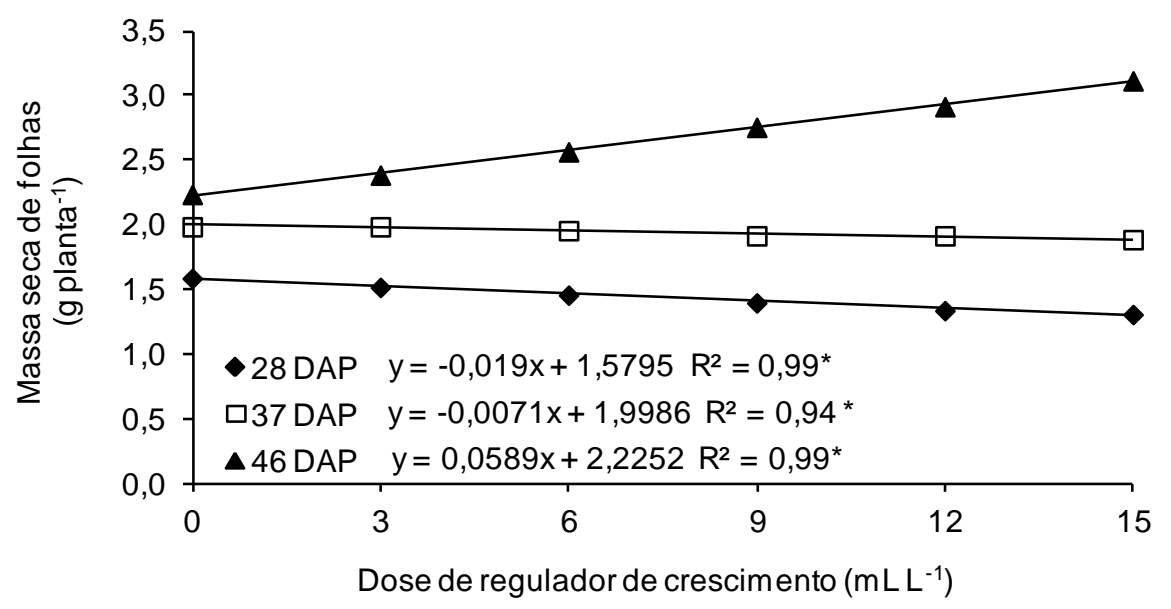

Figura 5 - Massa seca de folhas por planta em função das diferentes doses de regulador de crescimento aos 28; 37 e 46 DAP. *Significativo a 5\% de probabilidade, pelo teste F. Leaves dry mass per plant as a function of different plant growth stimulant doses at 28; 37 e 46 DAP. * Significant at the level of 5\% of probability according to the F-test.

A aplicação de Stimulate ${ }^{\circledR}$ em sorgo, no intervalo de doses de 10 a $13 \mathrm{~mL} \mathrm{~kg}^{-1}$ de sementes, e em trigo, no intervalo de doses de 3,5 a $5,0 \mathrm{~mL} \mathrm{~kg}^{-1}$ de sementes, proporcionou aumentos significativos na massa seca de parte aérea (Cato, 2006), comprovando que a utilização de regulador de crescimento também pode influenciar sobre o crescimento da parte aérea das plantas.

A produtividade de raízes tuberosas no campo não diferiu em função dos tratamentos aplicados, sendo as médias das produtividades total e comercial de 27,5 e $25,8 \mathrm{t} \mathrm{ha}^{-1}$, respectivamente. Assim, as alterações no número de raízes adventícias e de folhas nas plantas cultivadas no campo, ocorridas de maneira semelhante ao que aconteceu nos recipientes, em função das diferentes doses de Stimulate ${ }^{\circledR}$, não promoveram variação na produtivi- dade de raízes tuberosas. Em batata, Blat et al. (2010) também verificaram produtividade de tubérculos semelhante entre o tratamento-testemunha e os tratamentos nos quais foram utilizados Stimulate ${ }^{\circledR}$, sob diversas formas de aplicação.

Os resultados quanto à influência de Stimulate ${ }^{\circledR}$ na produtividade das culturas são controversos, e estudos com plantas cuja parte comercial é aérea são mais frequentes. Bernardes et al. (2010), Mortele et al. (2008) e Baldo et al. (2009) não constataram diferença de produtividade entre testemunha e plantas tratadas nas culturas de feijão, soja e algodão, respectivamente. Contudo, Abrantes et al. (2011), Bertolin et al. (2010), Albrecht et al. (2009) e Palangana et al. (2012) verificaram incremento de produtividade de feijoeiro, soja, algodoeiro e pimenteiro, respectivamente, 
quando da aplicação de doses adequadas do produto. Ressalta-se ainda que, segundo Mortele et al. (2008), a eficácia do produto é favorecida quando ocorrem condições climáticas adversas.

\section{Conclusão}

A utilização do regulador de crescimento Stimulate ${ }^{\circledR}$ nas doses testadas promove incremento no número de raízes adventícias de plantas de batatadoce, mas não na produtividade de raízes tuberosas.

\section{Referências}

Abrantes FL, Sá ME, Souza LCD, Silva MP, Simidu HM, Andreotti M, Buzetti S, Valério Filho WV, Arruda $\mathrm{N}$ (2011) Uso de regulador de crescimento em cultivares de feijão de inverno. Pesquisa Agropecuária Tropical 41(2):148-154.

Albrecht LP, Braccini AL, Ávila MR, Barbosa MC, Ricci TT, Albrecht AJP (2009) Aplicação de biorregulador na produtividade do algodoeiro e qualidade de fibra. Scientia Agraria 10(3):191-198.

Ataíde EM, Ruggiero C, Oliveira JC, Rodrigues JD, Barbosa JC (2006) Efeito de giberelina (GA3) e do regulador de crescimento 'Stimulate' na indução floral e produtividade do maracujazeiro-amarelo em condições de safra normal. Revista Brasileira de Fruticultura 28(3):343-346.

Baldo R, Scalon SPQ, Rosa YBCJ, Mussury RM, Betoni R, Barreto WS (2009) Comportamento do algodoeiro cultivar delta opal sob estresse hídrico com e sem aplicação de regulador de crescimento. Ciência e Agrotecnologia 33(n.spe):1804 -1812.

Bernardes TG, Silveira PM, Mesquita MAM (2010) Produtividade do feijoeiro irrigado devido a reguladores de crescimento e culturas antecessoras de cobertura. Bragantia 69(2):371-375.

Blat S, Suguino E, Branco RBF, Perdoná MJ, Scarpellini JR, Gentilin Junior O (2010) Reguladores vegetais no crescimento e produção da batata. Pesquisa \& Tecnologia 7(1). Disponível em <http://www.aptaregional.sp.gov.br/index.php?option =com_content\&view=category\&layout=blog\&id=10\&l temid=284 > . Acesso em: 04 abr. 2014.

Bertolin DC, Sá ME, Arf O, Furlani Junior E, Colombo AS, Carvalho FLBM (2010) Aumento da produtividade de soja com a aplicação de bioestimulantes. Bragantia 69(2):339-347.

Candido WDS, Silva RCP, Maia SSS, Silva AC, Coelho MFB (2012) Propagação da canelinha (Croton zehntneri Pax et Hoffm.) por estacas caulinares. Revista Verde de Agroecologia e Desenvolvimento Sustentável 7(2):45-49.
Cato SC (2006) Ação de regulador de crescimento nas culturas do amendoizeiro, sorgo e trigo e interações hormonais entre auxinas, citocininas e giberelinas. ESALQ (Tese de doutorado em Agronomia).

CEPAGRI (2014) Centro de Pesquisas Meteorológicas e Climáticas Aplicadas à Agricultura. Clima dos Municípios Paulistas. Disponível em < http://www.cpa.unicamp.br/outras-

informacoes/clima-dos-municipios-paulistas.html>. Acesso em 03 nov. 2014.

Dario GJA, Martin TN, Dourado Neto D, Manfron PA, Bonnecarrère RAG, Crespo PEN (2005) Influência do uso de fitorregulador no crescimento da soja. Revista da FZVA 12(1):63-70.

Dutra LF, Schwengber J, Tonietto A, Kersten E (1999) Enraizamento de estacas de ramos de pessegueiro (Prunus persica (L.) Batsch). Revista Brasileira de Agrociência 5(2):93-95.

EMBRAPA (1995) Empresa Brasileira de Pesquisa Agropecuária. Centro Nacional de Pesquisa de Hortaliças. Cultivo da batata-doce (Ipomoea batatas (L.) Lam), Brasília. 18p.

Gontijo TCA, Ramos JD, Mendonça V, Pio R, Araújo Neto SE, Corrêa FLO (2003) Enraizamento de diferentes tipos de estacas de aceroleira utilizando ácido indolbutírico. Revista Brasileira de Fruticultura 25(2):290-292.

IBGE - Instituto Brasileiro de Geografia e Estatística (2011) Sistema IBGE de recuperação automática SIDRA. Banco de dados Agregados. Disponível em $<$ http://www.sidra.ibge.gov.br/bda/tabela/protabl.asp $? c=1612 \& z=t \& o=11 \& \mathrm{i}=P>$. Acesso em 13 set. 2013.

Mayer NA, Pereira FM, Nachtigal JC (2001) Propagação do umezeiro (Prunus mume Sieb \& Zucc.) por estaquia herbácea. Revista Brasileira de Fruticultura 23(3):673-676.

Mortele LM, Santos RF, Lucca E, Braccini A, Scapim CA, Barbosa MC (2008) Efeito da aplicação de biorregulador no desempenho agronômico e produtividade da soja. Acta Scientiarum Agronomy 30(supl.):701-709.

Palangana FC, Silva ES, Goto R, Ono EO (2012) Ação conjunta de citocinina, giberelina e auxina em pimentão enxertado e não enxertado sob cultivo protegido. Horticultura Brasileira 30(4):751-755.

Pio R, Ramos JD, Chalfun NNJ, Gontijo TCA, Mendonça V, Carrijo EP, Chagas EA (2006) Propagação de estacas apicais de figueira: diferentes ambientes, ácido indolbutírico e tipo de estaca. Ciência e Agrotecnologia 30(5):1021-1026. 
Ramos JD, Matos LES, Gontijo TCA, Pio R, Junqueira KP, Santos FC (2003) Enraizamento de estacas herbáceas de 'Mirabolano' (Prunus cerasifera Ehrn) em diferentes substratos e concentrações de ácido indolbutírico. Revista Brasileira de Fruticultura 25(1):189-191.

Reghin MY, Otto RF, Silva JBC (2000) "Stimulate Mo" e proteção com "tecido-não-tecido" no pré enraizamento de mudas de mandioquinha salsa. Horticultura Brasileira 18(1):53-56.

Rós AB, Montes SMNM, Narita N, Tavares Filho J (2011) Technical viability of the production of sweet potatoes plantlets in trays. Semina: Ciências Agrárias 32(4):1423-1428.

Rós AB, Tavares Filho J, Barbosa GMC (2013) Produtividade da cultura da batata-doce em diferentes sistemas de preparo do solo. Bragantia 72(2):140-145.

Silva CP (2008) Enraizamento de estacas de pinheira (Annona squamosa L.), gravioleira (Annona muricata L.) e atemoeira (Annona squamosa L. X Annona cherimola L.) tratadas com ácido Indolbutírico (iba), ácido naftalenoacético (naa) e regulador de crescimento. UNESP (Tese de doutorado em Agronomia).
Taiz L, Zeiger E (2012) Fisiologia vegetal. Artmed. 954p.

Tecchio MA, Paioli-Pires EJ, Rodrigues JD, Vieira CRYI, Terra MM, Botelho RV (2005) Aplicação de regulador de crescimento nas características ampelométricas da infrutescência da videira 'Tieta'. Revista Brasileira de Fruticultura 25(2):300-303.

Vieira CRYI, Pires EJP, Terra MM, Tecchio MA, Vieira MDC (2008) Reguladores vegetais influenciando número e tamanho de células das bagas da uva 'Niagara Rosada'. Revista Brasileira de Fruticultura 30(1):25-30.

Vieira EL, Castro PRC (2002) Ação de Stimulate no desenvolvimento inicial de plantas de algodoeiro (Gossypium hirsutum L.). USP. 3p.

Vieira EL (2001) Ação de regulador de crescimento na germinação de sementes, vigor de plântulas, crescimento radicular e produtividade de soja (Glycine max (L.) Merrill), feijoeiro (Phaseolus vulgaris L.) e arroz (Oryza sativa L). ESALQ (Tese de doutorado em Agronomia).

Villa F, Pio R, Chalfun NNJ, Gontijo TCA, Dutra LF (2003) Propagação de amoreira-preta utilizando estacas lenhosas. Ciência e Agrotecnologia 27(4):829-834. 